\title{
MODELOS QUANTITATIVOS DE APOIO ÂS DECISÕES - I
}

Pierre Jacques Ehrlich Professor do Departamento de Informática $e$ Métodos Quantitativos da EAESP/FGV. E-mail Ehrlich@eaesp.fgvsp.br

RESUMO: Modelagem Quantitativa para Apoio às Decisões teve um grande desenvolvimento a partir da década de 60. Chegou-se a um processo normativo, dentro da tradição da Pesquisa Operacional. Dentro desta mesma tradição, os resultados foram cuidadosamente analisados por meio de análises de sensibilidade que criaram as condições para as suas implementações práticas. A evolução natural e necessária para Decisōes com multicritérios tem sido substancialmente mais controvertida. O processo "teoricamente correto" se revelou de dificil implementação prática. Surgiram "desafiantes" norte-americanos e europeus que, abandonando a estrutura normativa, procuram servir de Apoio às Decisões. O presente artigo apresenta e comenta este panorama com seus contrastes.

ABSTRACT: Quantitative Decision Support Modeling received most of its development during the 60's. The result was a normative procedure, following the Operations Research tradition. Following the same tradition, the results carefully analysed by sensitivity procedures allowed their practical implementations. The natural and required evolution towards Multicriteria Decisions has been much more controversial. The "theoretically correct" procedure presented difficulties for its practical implementation. North-American and European challengers appeared, where the normative structure was replaced by a Decision Support one. The paper presents and comments this panorama with its contrasts.

PALAVRAS-CHAVE: apoio à decisāo, modelo, análise, processo.

KEY WORDS: decision support, model, analysis, process. 
1. BECKMAN, 0. R., COSTA NETO, P. L. de 0 . Análise estatis. tica das decisōes. Blücher, 1980.

2. DPL - Decision Programming Language, da ADA Decision Systems.

3. VE (não levar) $=0,8 * 100+$ $0,2^{*} 0=80 ;$ VE (levar) $=0,8 * 80$ $+0,2^{\star} 60=76$.

4. Da empresa inglesa Krysalis.
A abertura da economia e a estabilidade da moeda têm seus reflexos sobre a racionalidade dos processos de decisăo nas empresas brasileiras. A Modelagem Quantitativa para A poio às Decisōes, que já teve seu atrativo, está retomando sua devida importância.

Sob a designação Modelos Quantitativos de Apoio às Decisões, é possível incluir desde simples planilhas em microcomputador até modelos de inteligência artificial, passando por todo o tradicional ferramental da pesquisa operacional. Vamos nos limitar ao que usualmente se denomina por Análise das Decisōes e por Decisóes Multiatributos ou Multicritérios ou com Objetivos Conflitantes. Este artigo fará uma revisão das técnicas tradicionalmente bem aceitas. No próximo número da RAE - Revista de Administração de Empresas, um segundo artigo tratará de técnicas mais controvertidas que estăo abrindo novos rumos.

Um processo de decisăo começa pela identificação do que eu desejo, do que posso fazer (alternativas) e da informação de que disponho. Espera-se que estes elementos, ordenados numa estrutura lógica, resultem na melhor decisāo possível. Quanto ao resultado, é preciso esperar que o acaso resolva as incertezas.

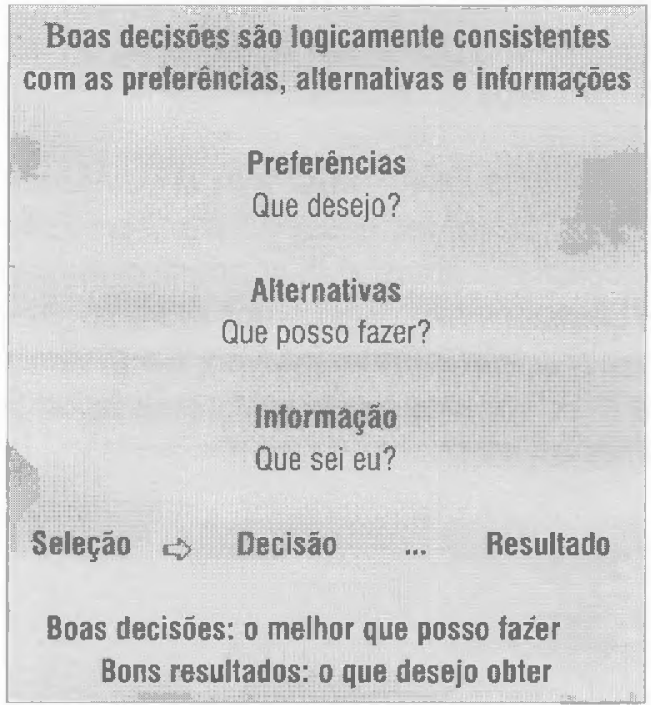

No cotidiano, a maioria das decisões não requer o auxílio de modelos, mas quando a decisão é importante (nas possíveis consequências), complexa (muitos aspectos a considerar), envolvendo muitas alternativas e distintos objetivos, quando necessita ser compartillhada por um grupo de pessoas ou quando envolve riscos, um modelo pode servir de grande apoio.

\section{A modelagem}

Um modelo é uma representação simplificada da realidade, mediante a qual procuramos identificar e destacar os elementos desta realidade que sejam os mais importantes para a decisão. No processo de modelagem, troca-se a riqueza e abrangência da realidade por poder de análise e capacidade de experimentação. Os elementos de um modelo são:

- variáveis de controle ou de decisão sobre as quais podemos atuar para atingir nossos objetivos;

- variáveis de estado ou da natureza sobre as quais não temos controle, mas que afetam as conseqüências ou resultados de uma decisão;

- estrutura do modelo - no âmbito do nosso estudo, corresponde a equaçōes matemáticas que "amarram" as relações no modelo;

- parâmetros - valores numéricos que entram nas equaçóes;

- critérios de decisâo ou preferências;

- objetivos ou metas.

Com o modelo, desejamos: analisar distintos cenários (esta experimentação seria impossível no contexto global da realidade); obter subsídios para uma tomada de decisão; verificar a estabilidade dos resultados de uma análise, quando de uma análise de sensibilidade.

A utilizaçāo de modelos para o apoio às decisões traz muitos benefícios, como:

- identificar os elementos relevantes para a decisão e descartar os irrelevantes;

- educar a intuição;

- comunicar e discutir a estrutura e os parâmetros;

- analisar situaçōes complexas;

- analisar muitas alternativas;

- comunicar resultados;

- analisar a estabilidade dos resultados. 
Vejamos um exemplo bem simples que nos apresentará os elementos do modelo.

\section{Exemplo}

Vou sair de casa e hoje, mas parece que vai chover. Considerando que meu objetivo é maximizar meu conforto, devo levar guarda-chuva ou não?

O processo da modelagem começa pela identificação da variável de decisão - levar guarda-chuva ou não (apenas duas alternativas) - e da variável de estado da natureza (sobre a qual nāo tenho controle): chove ou não.

Observo que a combinação entre as variáveis de estado e de decisão produzem quatro situaçōes que, subjetivamente, valorizo numa pontuaçāo de zero a cem, desta forma:

\begin{tabular}{|lcc|}
\hline Decisăo & \multicolumn{2}{c|}{ Natureza } \\
& Chove & Näo Chove \\
\hline Levar & 60 & 80 \\
Năo levar & 0 & 100 \\
\hline
\end{tabular}

\section{Ou seja:}

- nāo levar guarda-chuva e não chover é o ideal, vale 100 pontos;

- não levar guarda-chuva e chover é a pior situaçāo, vale zero pontos;

- levar guarda-chuva e não chover é apenas um pouco desagradável, vale 80 pontos;

- levar guarda-chuva e chover é mais desagradável, vale 60 pontos.

Cada decisāo me conduz a uma loteria: "chove/não chove". Assim, já identificamos os três elementos: decisão, incerteza

\section{Figura 1}

DIAGRAMAS DE INFLUÊNCIA - OS ELEMENTOS

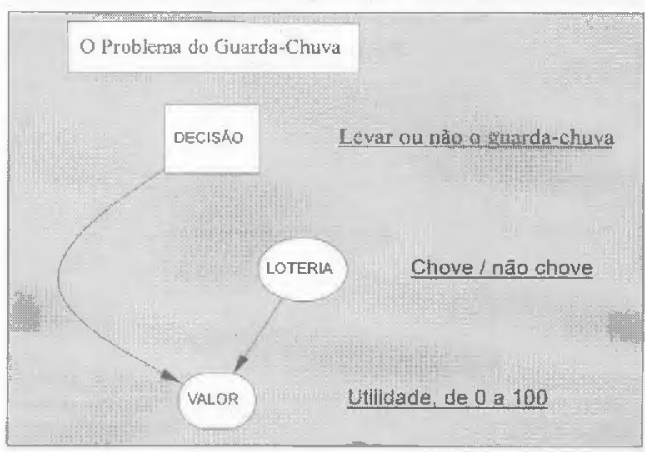

(loteria sobre o estado da natureza) e valores (para as conseqüências). Esta estrutura é representada no diagrama de influências representado na figura 1. Utilizamos o software DPL para modelar este problema.

Este mesmo modelo pode ser representado sob a forma de árvore, como na figura 2.

Figura 2 ÁRVORE COMPACTA O PROBLEMA DO GUARDA-CHUVA

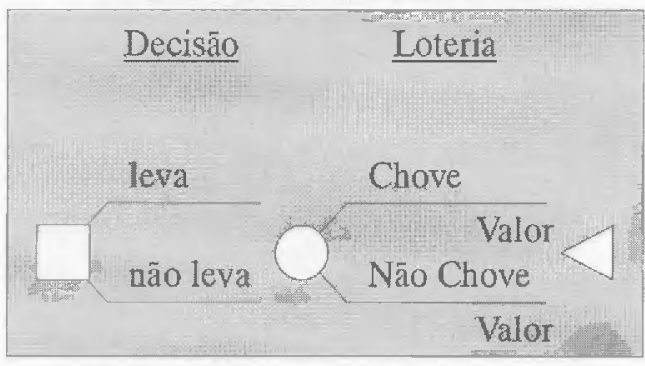

Para continuar, necessitamos de uma informaçāo - qual a probabilidade de chover? - e de um critério para "trocar" a loteria da incerteza. A informaçāo é a de que, para hoje, a probabilidade de chuva é de $20 \%$. O critério de "troca" da loteria é pelo seu valor esperado VE.

Resolvendo com o software, decidimos por nāo levar guarda-chuva, como mostra a figura 3 .

Figura 3 ÁRVORE DETALHADA O PROBLEMA DO GUARDA-CHUVA

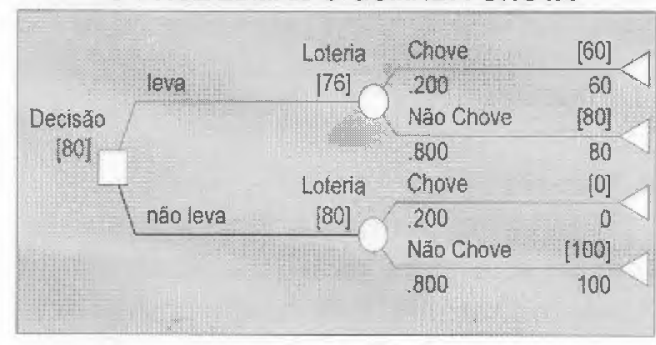

Finalmente, desejamos ter uma avaliaçāo do risco associado a esta decisão. Ele é alto, pois a informação sobre a probabilidade de chuva não é totalmente confiável, e, refazendo os cálculos, se esta probabilidade fosse superior a $25 \%$, inverteríamos a decisão.

Apesar de muito simples, tal exemplo passou pela maioria das etapas da modelagem, que estāo resumidas no quadro 1 . 


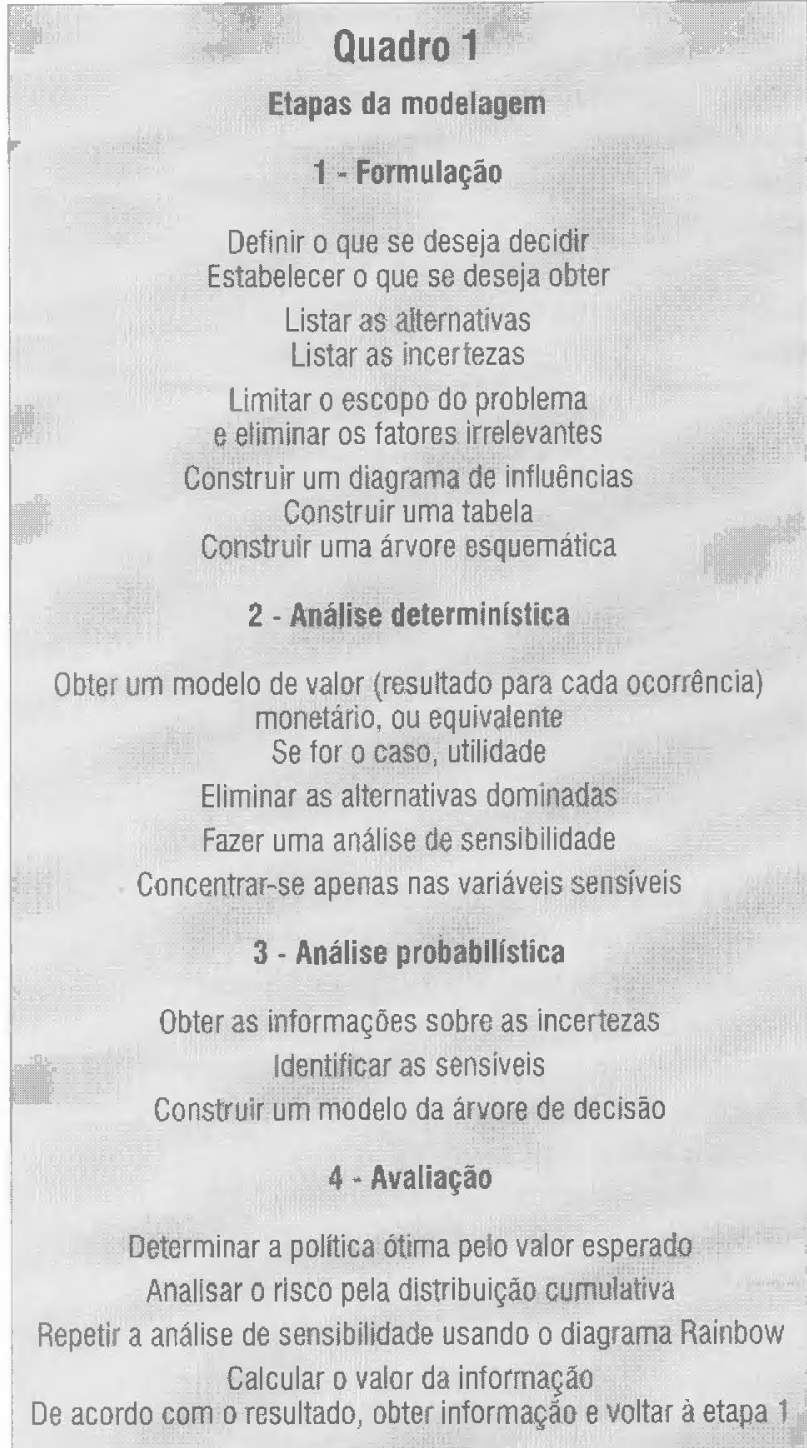

5 - Apresentaçāo dos resultados e do resumo das análises grande atualidade), passou a ser mais avaliado pelos resultados das análises de sensibilidade. Para mostrar o poderio destas ferramentas, apresenta-se mais um exemplo com alguns comentários.

\section{Exemplo}

Uma empresa acaba de desenvolver um novo produto e precisa decidir sobre o processo de distribuição: fabricar e vender ou licenciar para terceiros e só receber os direitos da licença. Na primeira opçāo, há custos de marketing (loteria) e de produção (loteria), e a receita é dada pelo volume de vendas (loteria que depende dos custos de marketing) e do preço unitário (fixo). Na segunda opção, recebe-se a taxa de licença pelo volume de vendas.

Sem entrar nos detalhes dos valores, o diagrama de influência é aquele apresentado na figura 4, e a árvore de decisão, na figura 5. O resultado aparece na forma da figura 6 .

O risco pode ser visualizado pelas distribuições cưmulativas superpostas (em microcomputador seria colorido, uma cor para cada alternativa), como na figura 7 . Embora esta apresentaçáo por meio de distribuições cumulativas seja excelente para a visualização do risco, requer um pouco de treino.

As linhas verticais mostram os valores esperados (VE) para as duas alternativas: 36 para "licença" e 39,6 para "nós mesmos".

A alternativa "licença" conduz a apenas uma loteria com três possibilidades, sendo os resultados: i) $40 \%$ de lucro igual

\section{A ferramenta}

No passado, muitos softwares foram desenvolvidos para construir Modelos de Apoio às Decisóes. Este campo passou pela mesma evolução de tantos outros. Alguns softwares mantiveram a simplicidade e tornaram-se macros-suplementares (add-in) de planilhas. Outros (como o DPL ou o Supertree) tornaram-se ferramentas extremamente poderosas, que operam em ambiente Windows (há poucos para Macintosh, mas vale mencionar o Demos, da Lumina). A maioria desapareceu. Graças ao poderio dos softwares, o aspecto risco, que tradicionalmente era tratado pela teoria da utilidade (cujos conceitos continuam de
Figura 4

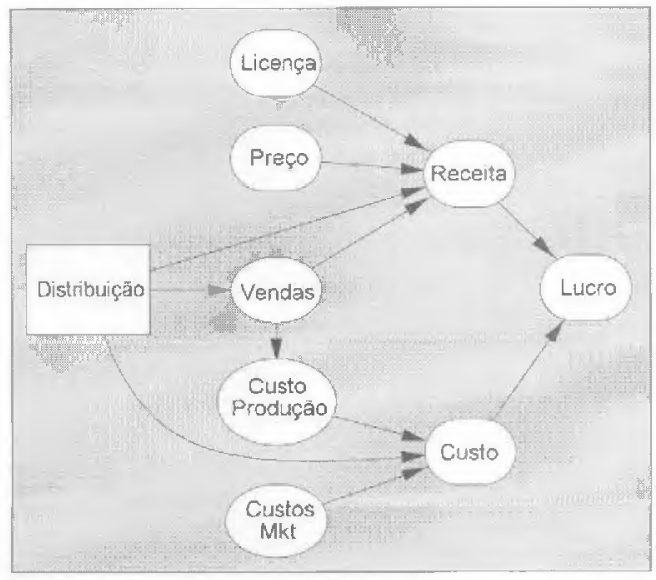


Figura 5

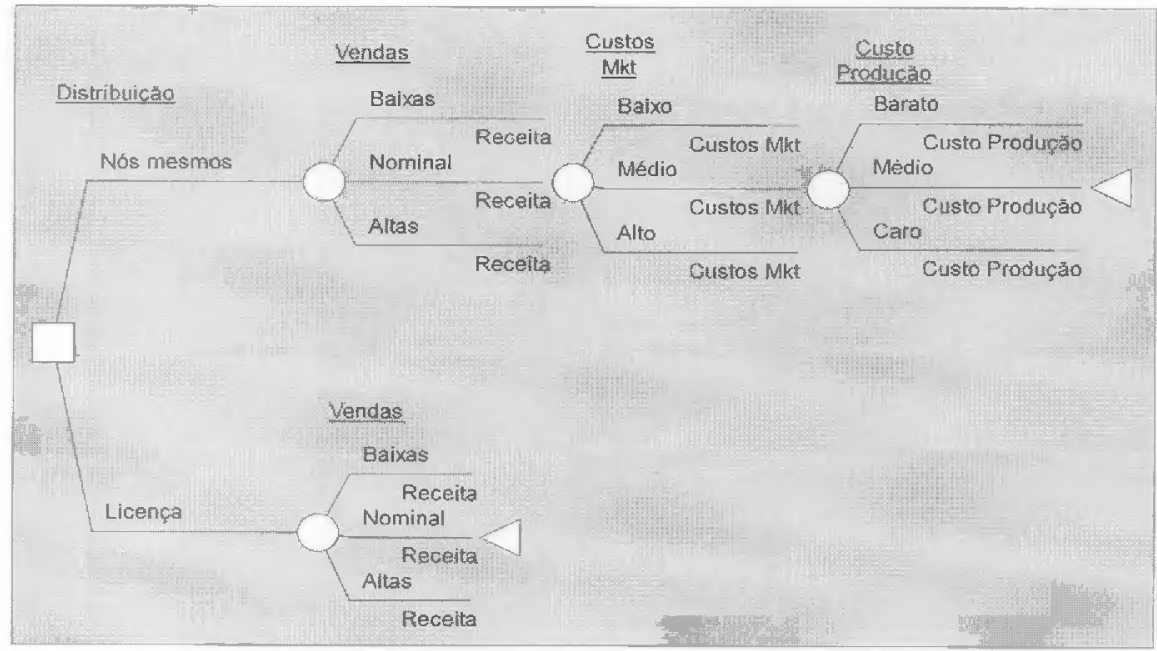

a 20 ; ii) $40 \%$ de lucro igual a 40 ; iii) $20 \%$ de lucro igual a 60; resultando em: VE (licença) $=0,4^{*} 20+0,4^{*} 40+0,2^{*} 60=36$.

A leitura da cumulativa é da esquerda para a direita: $40 \%$ de valor $20 ; 80 \%$ de valor 40 ou menos; $100 \%$ de valor 60 ou menos.

A alternativa "nós mesmos" foi preferida por resultar num maior VE $(39,6)$. A leitura (aproximada) da cumulativa é: $0,01 \%$ de valor $-10 ; 0,25 \%$ de valor $-0,5$ ou menos; $0,3 \%$ de valor 0 ou menos; ...; $75 \%$ de valor 62 ou menos; $87 \%$ de valor 65 ou menos; $100 \%$ de valor 80 ou menos.

Ela é mais arriscada, pois tem até uma probabilidade (de cerca de $0,3 \%$ ) de resultar em lucro negativo (prejuízo). O máximo chega a cerca de 80 .
Figura 6

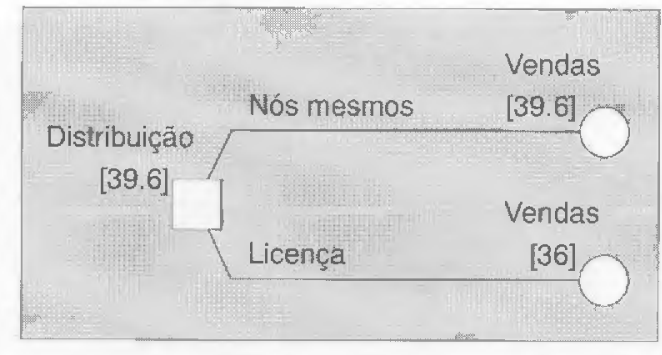

A cumulativa para a alternativa "nós mesmos" isolada permite melhor visualizaçāo (figura 8). A árvore detalhada é apresentada na figura 9.

O diagrama Rainbow para o preço unitário de venda mostra que, pouco abaixo do valor 2 , que é o inicialmente estabele-

Figura 7

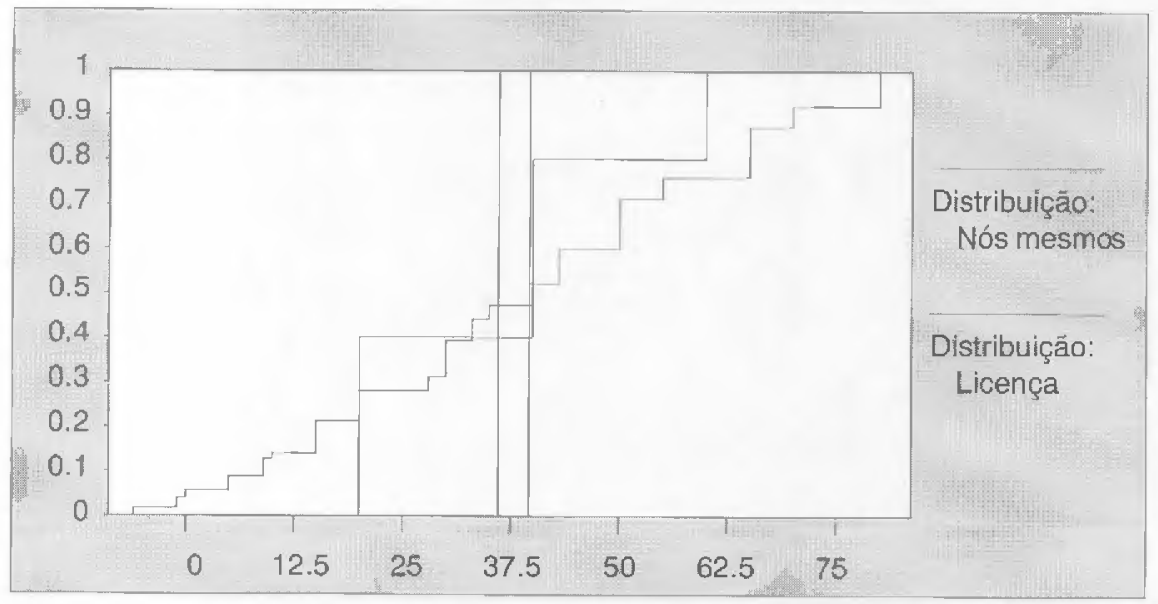

RAE - v. 36 - ก. 1 - Jan./Fev./Mar. 1996 
Figura 8

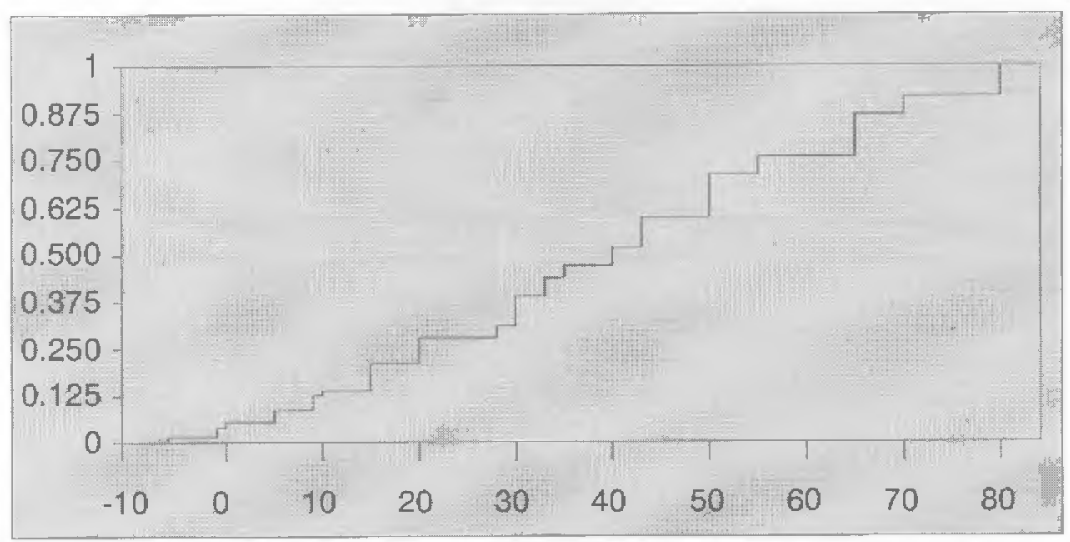

Figura 9

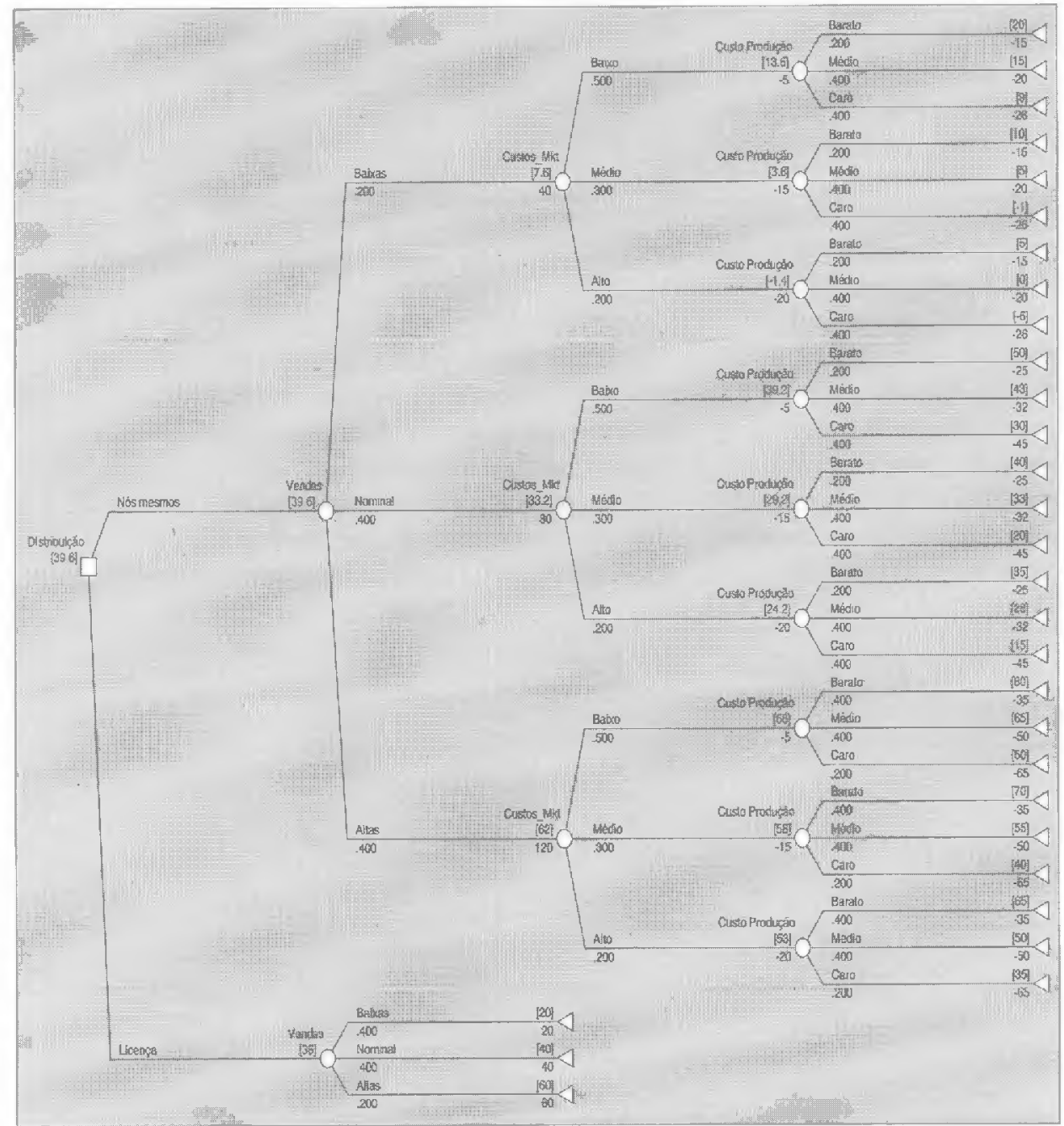


cido, há uma mudança de política e que seria melhor licenciar (figura 10).

O gráfico "tornado" (figura 11) permite visualizar uma análise de sensibilidade para dois parâmetros: preço de venda (entre 0 e 3) e taxa de licença (entre 0 e 2). Observamos os pontos de alteraçāo de política, assim como os respectivas VE para os lucros. Não há proporcionalidade de escalas para os parâmetros.

O gráfico tornado também permite fazer uma análise de sensibilidade para as loterias (incertezas).

\section{Multicritérios e grupo}

Este tópico, extremamente rico em idéias e escolas de pensamento, será, em princípio, assunto do próximo artigo. Entretanto, para completar o âmbito de análise deste primeiro artigo, apresenta-se um material que recai no "usualmente aceito", mediante um exemplo de introduçăo ao software Hiview. Este tanto pode ser utilizado para problemas com multicritérios em geral (como será discutido no próximo artigo), como para decisões em grupo, que parece ser o forte das suas aplicaçōes.

O comportamento de um grupo apresenta particularidades que exigem:

- eventuais sacrifícios teóricos para garantir a facilidade de compreensão do processo por todos os membros do grupo;

- facilidade de comunicação;

- clara explicitaçăo das metas;

- clara explicitação das importâncias das submetas:

- clara explicitação das preferências ao longo de cada critério;

- redução das ambiçōes do analista, ao produzir um modelo que poderá ter distintos usos nas māos dos membros do grupo.

\section{Exemplo}

Deseja-se escolher um novo microcomputador para equipar a empresa. $\mathrm{O}$ objetivo global é o de selecionar o melhor PC. A decomposição hierárquica do que seja "melhor" pode variar de um analista para outro. No exemplo em pauta, o nó-raiz PC foi caracterizado por dois critérios (que originam dois nós): costs e benefits. A decomposição hierárquica total é a da figura 12.
Figura 10

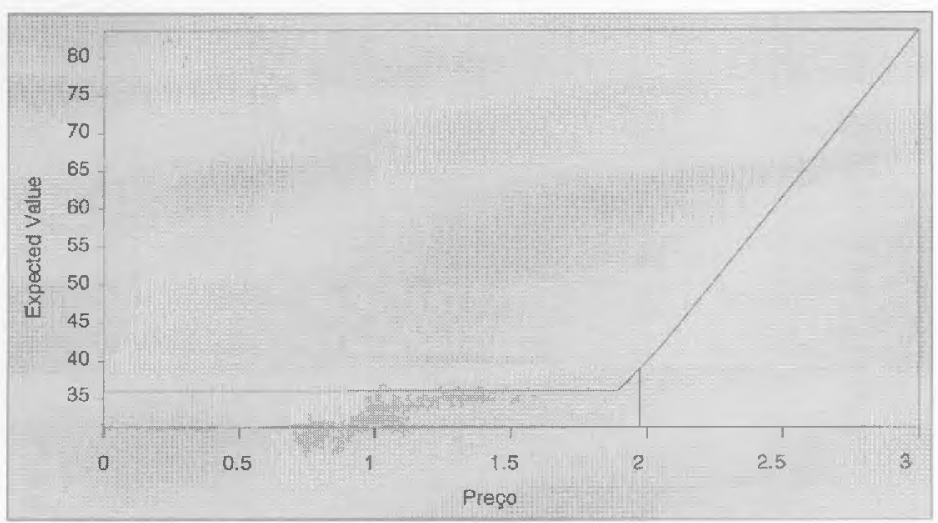

Figura 11

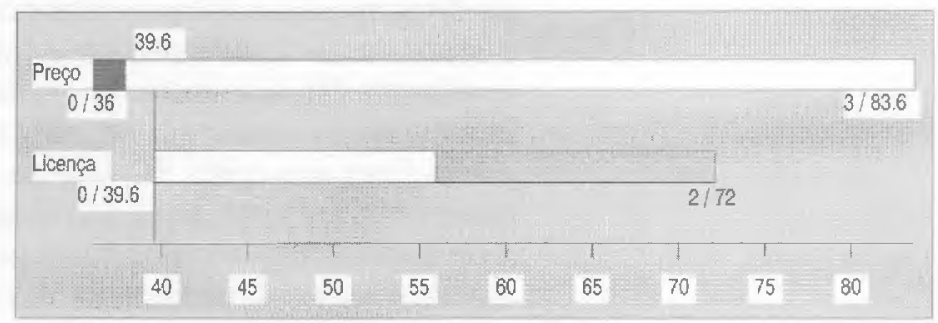

Figura 12

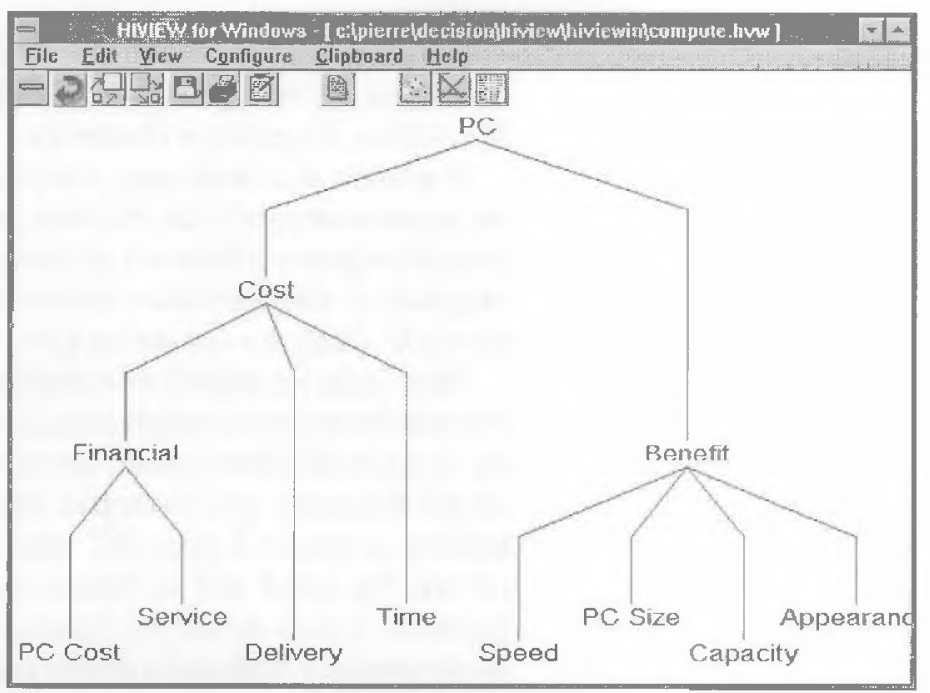




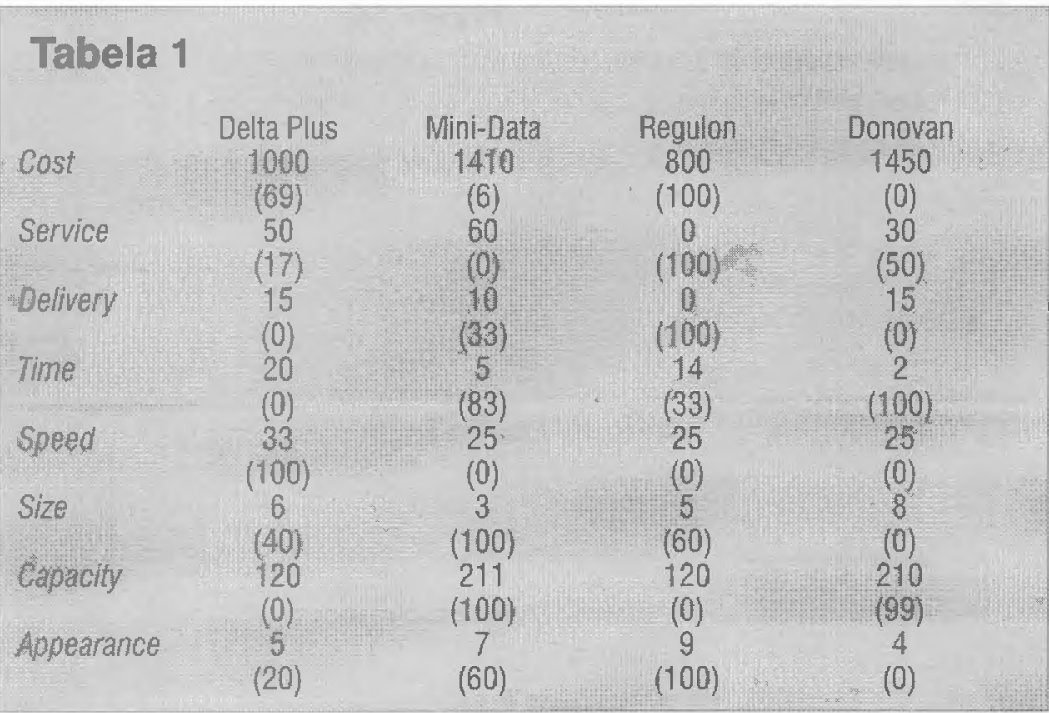

Agora é preciso encontrar uma escala de mensuração da preferência para cada um dos oito critérios últimos nas pontas da decomposição. Estas escalas podem ser quantitativas (cardinais) ou qualitativas (ordinais). Hiview exige que todas as escalas acabem sendo quantitativas entre 0 e 100. Para um custo PC cost de compra entre $£ 800$ e $£ 1.450$, é preciso caracterizar a preferência como inversa, e o programa atribui o valor 0 ao preço mais alto $(£ 1.450)$ e o valor 100 ao preço mais baixo ( $£ 800$ ). Aos outros preços são automaticamente atribuídos valores numa escala proporcional linear. Vale o mesmo para «tempo de entrega ", ou qualquer outro critério. Também seria possível atribuir diretamente o valor na escala de 0 a 100 (e neste caso os valores poderiam refletir uma preferência nāo linearmente proporcional ao preço).

Foram identificadas quatro alternativas (modelos de computadores): Delta Plus, Mini-Data, Regulon e Donovan.

A matriz dos atributos, correspondentes aos seus respectivos critérios, para cada uma das quatro alternativas, nas medidas originais e nas medidas relativas (numa escala 0 - 100), é exposta na tabela 1 .

Para cada nó (nível) sāo atribuídos pesos relativos que caracterizam a importância dos constituintes deste nível. An nível do nó financial, por exemplo, foram atribuídos os pesos 5 para PC cost e 1 para service. No nível cost os pesos são 9 para financial, 1 para delivery e 2 para time. Evidentemente, a atribuiçāo destes pesos é um dos principais elementos de negociaçāo no grupo de decisāo. Resultou a seguinte matriz global dos pesos atribuídos:

$\begin{array}{lll}\text { PC cost: } 5 & \text { Financial: } 9 & \\ \text { Service: } 1 & \text { Delivery: } 1 & \text { Cost: } 50 \\ & \text { Time: } 2 & \\ & & \\ & \text { Speed: } 10 & \\ & \text { PC size: } 2 & \text { Benefit: } 50 \\ & \text { Capacity: } 8 & \\ & \text { Appearance: } 3\end{array}$

Após o processo de rateio proporcional, de modo que a cada nível correspondam 100 pontos, resultaram os pesos relativos dos oito critérios:

$\begin{array}{cccc}\text { PC cost } & \text { service } & \text { delivery } & \text { time } \\ 31,25 & 6,25 & 4,17 & 8,33 \\ & & & \\ \text { speed } & \text { size } & \text { capacity } & \text { appearance } \\ 21,74 & 4,35 & 17,39 & 6,52\end{array}$

A utilidade global de cada alternativa é obtida pela soma das oito medidas relativas, ponderadas pelos pesos acima (resposta numa escala 0 - 100). Ela classifica as quatro alternativas:

\section{1 - Regulon: 53,57 \\ 2 - Delta Plus: 47,46 \\ 3 - Mini-Data: 35,91 \\ 4 - Donovan: 28,66}

Hiview permite elaborar diversos tipos de análises de sensibilidade. A agregaçāo aditiva das medidas relativas, com a determinação dos pesos para esta agregação, é particularmente simples. A finalidade é garantir a compreensão do processo pelos atores, assim como a comunicaçāo entre eles. Em particular, o processo de decisāo que utiliza Hiview como apoio nos obrigou a passar por três etapas importantes:

- decomposição hierárquica do objetivo em critérios (e subcritérios);

- estabelecimento de uma preferência para cada critério (ou subcritério). No caso do Hiview, foi uma simples escala de proporção linear, mas, na medida do possível, obrigou-nos a adotar uma métrica para cada atributo. Geralmente, preferências são dados objetivos (mensuráveis); 


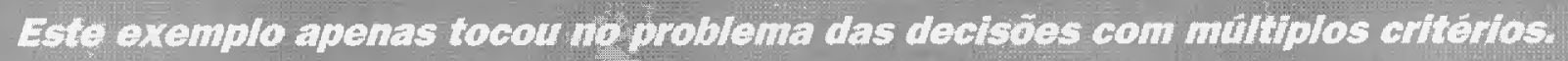

No woximo ardigo apresentaremos as tres metodoledtes que seguem formallenes

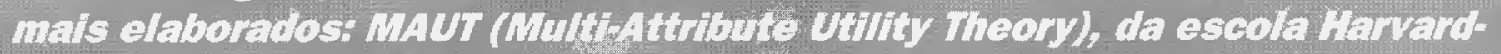

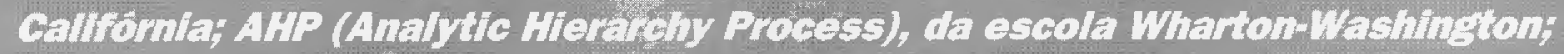

o MCDA (Murtontorla Decleton Atd), da escola guopela (principalmente francofond), con sel processo de outranking (desclassiftoagão).

- comparações entre critérios de modo a estabelecer níveis de importância. Frequientemente, importâncias são valores subjetivos.

O exemplo também ilustra uma forma muito comum de conduzir um processo de decisão: a decomposição hierárquica inicial dividida em custos e em benefícios. De fato, a visualizaçăo dos resultados pela relação [benefícios/custos] ou, às vezes, pela diferença [benefícios - custos] costuma corresponder ao modo de raciocínio dos grupos de decisāo. Sempre no intuito de facilitar a compreensão e a comunicação, alguns autores recomendam este tipo de decomposição e de apresentação. Apresentam-se na tabela 2 os resultados numa forma de [custos] e de [benefícios]. Para fins de consistência, invertemos a escala dos custos associados a cada alternativa.

Também é comum apresentar estes resultados num gráfico tendo os custos no eixo horizontal e os benefícios no eixo vertical, de modo a visualizar a "fronteira eficiente". A figura 13 foi produzida por Hiview, de modo que a escala de PC costs está invertida. O modelo Regulon é o de menor custo. $O$ modelo Donovan está fora da "fronteira eficiente" e pode ser eliminado sem maiores consideraçóes.

Este exemplo apenas tocou no problema das decisōes com múltiplos critérios. No próximo artigo apresentaremos as três metodologias que seguem formalismos mais elaborados: MAUT (Multi-Attribute Utility Theory), da escola Harvard-Califórnia; AHP (Analytic Hierarchy Process), da escola Wharton-Washington; e MCDA (Multi-Criteria Decision Aid), da escola européia (principalmente francófona), com seu processo de outranking (desclassificação).

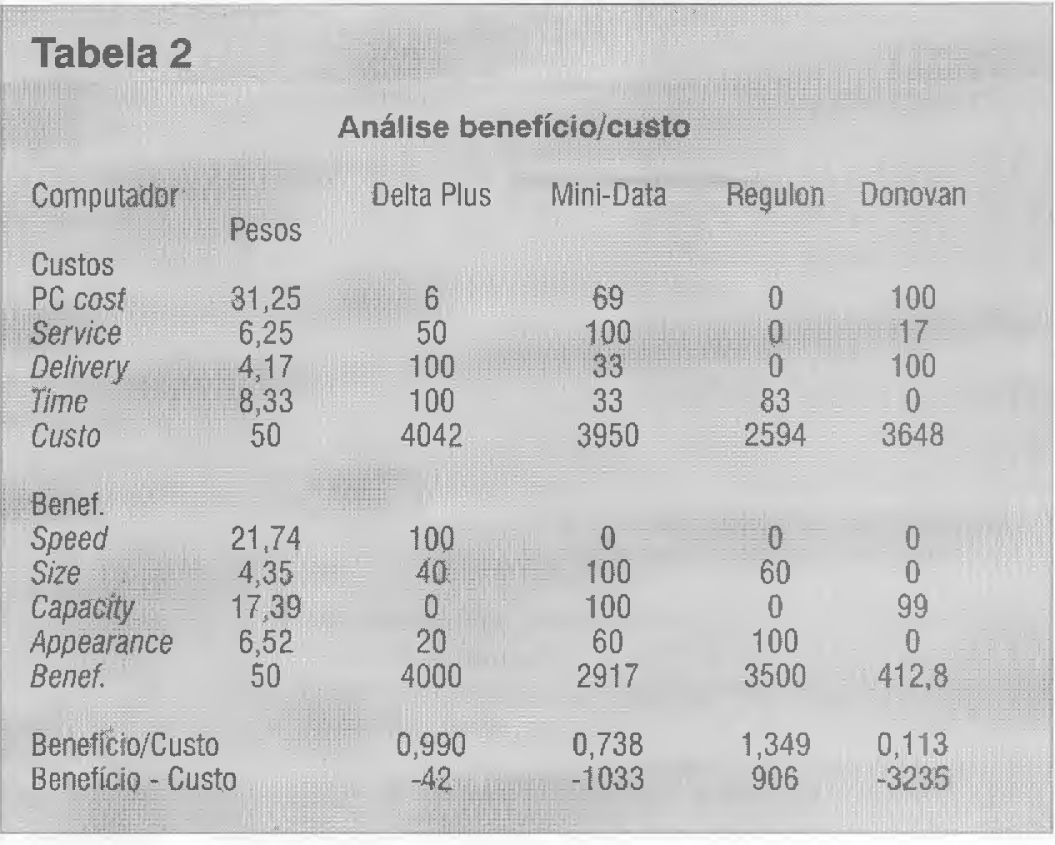

Figura 13

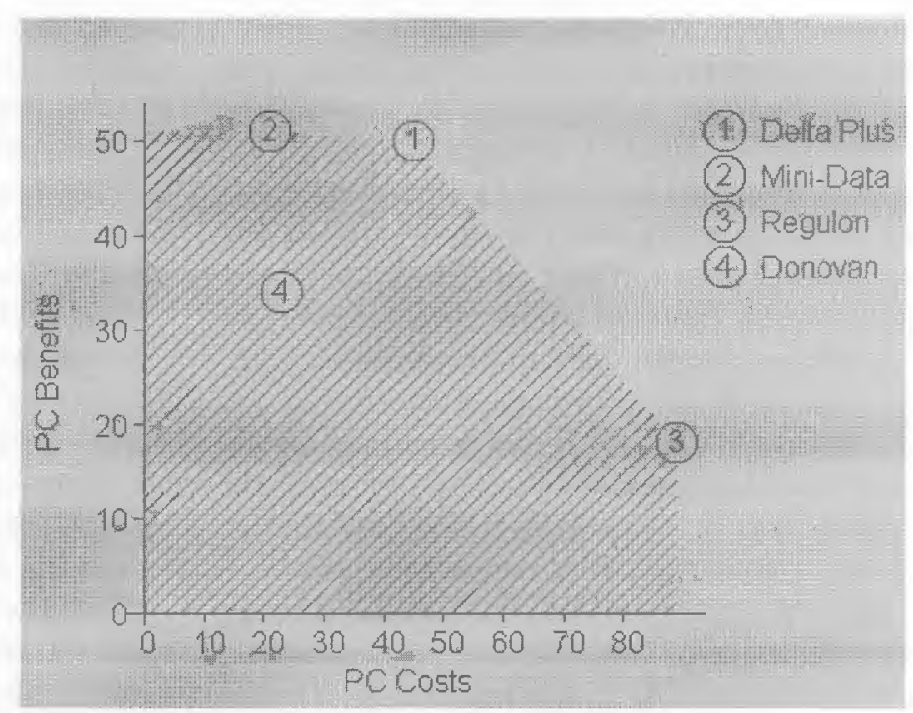

